\title{
ESTADO ACTUAL DEL CONTROL DE LEGALIDAD DE LOS ACTOS ADMINISTRATIVOS. ¿QUÉ QUEDA DE LA NULIDAD DE DERECHO PÚBLICO?
}

\author{
Jorge Bermúdez Soto*
}

\begin{abstract}
RESUMEN
En este trabajo se plantea como tesis que la teoría de la nulidad de Derecho público ha sufrido una serie de retrocesos desde su formulación, los que tienen su origen tanto en los cambios legislativos como en la evolución de la jurisprudencia. Esta situación es posible de ser apreciada en tres ámbitos. En primer lugar, en la inclusión de una especie de ilegalidad tolerada, a partir de la entrada en vigor de la Ley $N^{\circ} 19.880$, en que sólo es un vicio del acto administrativo aquel que, ocurrido durante el procedimiento, tiene alguna entidad o importancia. En segundo término, el retroceso del recurso de protección como paliativo a un contencioso-administrativo, sobre todo a partir del resultado imprevisible del examen de admisibilidad. Finalmente, en la jurisprudencia, la cual ha desmembrado casi por completo la nulidad. Esta serie de retrocesos, más que plantear un problema dogmático, constituye una situación grave para la vigencia del Estado de Derecho en su conjunto.
\end{abstract}

\section{NULIDAD DE DERECHO PÚBLICO - ACTO ADMINISTRATIVO - NULIDAD ADMINISTRATIVA}

\section{Present state of legal control in administrative actions: What is left after of public law annulment?}

\begin{abstract}
This work sets as a thesis that the annulment theory in Public Law has suffered a series of backwards steps since it was formulated: both those whose origins lie in legislative shifts as well as in courts decisions evolution. This situation can be noticed from three view points. First of all, in the admission of a kind of tolerated illegality in Act $N^{\circ} 19.880$, as an administrative act is considered foul only when the defect in its procedure possesses some entity or importance. In second term, in the backward step of the recurso de protección as a palliative towards an administrative-contentious act, specially considering the unpredictable result of its admissibility exam. Finally, in courts decisions, which had practically dismembered annulment. This series of backwards steps, more than setting a dogmatic problem, constitute a serious danger for the Rule of Law's effectiveness.
\end{abstract}

\section{PUBLIC LAW ANNULMENT - ADMINISTRATIVE ACT - ADMINISTRATIVE ANNULMENT}

* Abogado, Doctor en Derecho, Profesor de Derecho Administrativo en la Pontificia Universidad Católica de Valparaíso, Valparaíso, Chile. jorge.bermudez@ucv.cl

Artículo recibido el 25 de marzo de 2010 y aceptado para su publicación por el Comité Editorial el 28 de mayo de 2010. 


\section{INTRODUCCIÓN}

$\mathrm{P}$ arece mentira que aún sea necesario volver sobre el ya manido tema de la nulidad del acto administrativo. Si este tópico pretendiese ser planteado en el equivalente a nuestras Jornadas de Derecho Público en otros lugares, como en Alemania, donde se celebra la reunión anual de la asociación alemana de profesores de Derecho público, sin duda que el tema habría sido desechado de plano por su obviedad, falta de novedad y casi imposible avance real desde el punto de vista dogmático. Ello es así en general en el Derecho comparado que, normalmente, se utiliza de modelo en Chile, porque el tema de la revisión y anulación del acto administrativo se encuentra resuelto doctrinaria, jurisprudencial y legislativamente. Sin embargo, nada de ello ocurre en nuestro país.

Ya hace más de una década el profesor Soto Kloss se admiraba porque el tema de la nulidad de Derecho público "de modo inexplicable ha tenido tan poca resonancia en nuestra doctrina". Sin embargo, es probable que durante la década de los noventa e inicios del presente siglo la nulidad de los actos de la Administración haya vivido su momento de gloria. Y ello porque en un primer momento la doctrina de la denominada "Nulidad de Derecho Público" -que, como se sabe, es la denominación que ha recibido comúnmente en nuestro derecho la sanción a la actuación ilegal de la Administración del Estado- pareció asentarse sin contrapeso tanto en la doctrina de los profesores de Derecho administrativo como en la jurisprudencia de los tribunales de justicia.

Hoy en día la situación es distinta y existen motivos fundados para preguntarse qué queda de una teoría que quizá fue proclamada como dogma, quizá, anticipadamente.

En el presente trabajo se hará una breve referencia a la conceptualización del acto administrativo, que es el objeto del control de legalidad y su calidad de presunción de legitimidad, para luego adentrarse en los cambios que ha experimentado el panorama legislativo y sobre todo jurisprudencial, en torno al control de legalidad de la actuación jurídica de la Administración del Estado.

\section{Esplendor y declive de la Nulidad de Derecho Público}

La revisión de la legalidad de los actos de la Administración del Estado por parte de los tribunales de justicia fue aceptada rápidamente a contar de la década de los noventa. Ello coincide con la eliminación de la expresión "contencioso administrativo" de la Constitución de 1980, producto de las 54 primeras reformas que se introdujeron en el texto constitucional a fines de 1989. Con ello desaparecía el argumento histórico utilizado para eludir el control judicial, al menos, respecto de la legalidad de la actuación administrativa. Aunque, en la práctica, el Consejo de Defensa del Estado hasta hace

${ }^{1}$ Soto Kloss, E., Derecho Administrativo, Bases Fundamentales, Tomo II, El principio de Juridicidad, Ed. Jurídica de Chile, Santiago, 1996, p. 165. 
algún tiempo seguía interponiendo la excepción de incompetencia en todos los juicios intentados por la vía ordinaria en contra del Fisco.

También favoreció a este auge de la teoría de la nulidad de Derecho público la situación política de nuestro país. Un gran número de demandas de nulidad de Derecho público se interpusieron, una vez retornada la democracia, para demandar por actos ilegales o inconstitucionales de la Junta Militar de Gobierno, en particular respecto de actuaciones expedidas entre 1973 y 1978. Resultaba entonces que las demandas de nulidad, con todas las características que la doctrina le había adosado a la acción y que se basaba de forma directa en la Constitución de 1980, servían para enmendar actuaciones ilegítimas, producidas 10 o 15 años antes, perpetradas por el propio Gobierno que luego dictó la Constitución.

Pero la nulidad no era útil sólo para un sector político, ya que, dado que cualquier vicio, por nimio que fuera, viciaba al acto administrativo, permitió frenar la actuación o incluso el intento de ella por parte de los primeros gobiernos de la coalición gobernante. Entonces, cualquier intento de modificación del statu quo vigente podía ser rápidamente contenido por la vía de la acción de nulidad de Derecho público. Había entonces razones para que todos estuvieran satisfechos.

Sin embargo, esta situación comenzó a cambiar a partir de la ocurrencia de dos hitos trascendentales para el Derecho administrativo chileno: la entrada en vigor de la Ley No 19.880 y la incorporación de un criterio de distinción entre las dos acciones que, normalmente, se interponen a propósito de la impugnación de un acto administrativo.

\section{El aCto AdMinistrativo COMO DECisión DE APLICACión DEL ORDENAMIENTO JURÍDICO QUE SE PRESUME LEGÍTIMA}

Con fecha 29 de mayo de 2003 aparece publicada, prácticamente sin aviso, la Ley $\mathrm{N}^{\circ} 19.880$ que "establece bases de los procedimientos administrativos que rigen los actos de los órganos de la Administración del Estado” (en adelante LBPA). Dicha ley, a pesar de todas las críticas que se le puedan formular ${ }^{2}$, ha sido en la práctica un hito en la evolución del Derecho administrativo chileno. En dicho cuerpo legal se dispone en su art. 3 lo siguiente:

"Concepto de acto administrativo. Las decisiones escritas que adopte la Administración se expresarán por medio de actos administrativos.

Para efectos de esta ley se entenderá por acto administrativo las decisiones formales que emitan los órganos de la Administración del Estado en las cuales se contienen declaraciones de voluntad, realizadas en el ejercicio de una potestad pública”.

\footnotetext{
${ }^{2}$ Cfr. Soto Kloss, E., “La Ley 19.880 sobre procedimientos administrativos, ¿Aleluya o Miserere?”, en Ley 19.880 sobre procedimientos administrativos, Conferencias, Academia de Derecho Santo Tomás de Aquino, Santiago de Chile, año 2003.
} 
Más adelante, en el inciso final del art. 3 se disponen las características del acto administrativo:

"Los actos administrativos gozan de una presunción de legalidad, de imperio y exigibilidad frente a sus destinatarios, desde su entrada en vigencia, autorizando su ejecución de oficio por la autoridad administrativa, salvo que mediare una orden de suspensión dispuesta por la autoridad administrativa dentro del procedimiento impugnatorio o por el juez, conociendo por la vía jurisdiccional”.

Resulta fundamental dentro del concepto de acto administrativo el carácter de decisión o resolutivo que éste tiene. Ello quiere decir que a través del acto administrativo lo que hace la Administración del Estado es tomar una decisión de aplicación del ordenamiento jurídico a un caso concreto en una determinada forma. En efecto, lo que hace el ente público a través del acto es resolver una determinada manera de aplicar o ejecutar el ordenamiento jurídico público a un caso en particular que puede afectar o favorecer a una persona, un grupo de personas o incluso a la comunidad en su conjunto.

Este extremo de la definición legal se encuentra en consonancia con las definiciones del Derecho comparado. En efecto, para el prof. Alfredo Gallego Anabitarte, "el acto administrativo es la resolución (medida, decisión) unilateral de un sujeto en el ejercicio de poder público para un caso concreto". En el mismo sentido puede ser citada la definición de Hartmut Maurer, el acto administrativo es una regla imperativa para un caso concreto, emanada de una autoridad administrativa, con efecto externo directo ${ }^{3}$.

En el otro extremo se encuentra la definición que entiende al acto administrativo como una manifestación de la voluntad de la Administración Pública; en tal sentido, la doctrina administrativista más reputada entiende al acto administrativo como "la declaración de voluntad, de juicio, de conocimiento o de deseo realizada por la Administración en ejercicio de una potestad administrativa distinta de la reglamentaria" ${ }^{4}$. Podría decirse, entonces, que el legislador de la LBPA fue bastante ecléctico pues entiende que el acto administrativo es una decisión formal de la Administración del Estado, en la que se contiene su declaración de voluntad.

El problema de la definición legal radica en que no se señala que el acto administrativo sea una declaración de voluntad unilateral, de manera de distinguirlo del contrato administrativo. El acto administrativo - la resolución- se impone sin necesidad de que su destinatario manifieste su conformidad con el mismo.

A pesar de la definición ecléctica, el acto administrativo tiene como carácter esencial que en él se resuelve frente a un caso concreto, por lo que se distingue de otras actuaciones como las de tipo normativo (reglamento), que regulan de forma abstracta un número indeterminado de casos provocando una innovación en el ordenamiento jurídico; o de otro tipo de actuaciones que no resuelven sino que certifican, interpretan, manifiestan, una opinión,

${ }^{3}$ Maurer, H., Verwaltungsrecht, Ed. Beck 12a edición, Munich, 1999, p. 179.

${ }^{4}$ García de Enterría, E. y Fernández Rodríguez, T. R. en su Curso de Derecho Administrativo, Tomo I, p. 522, $7^{\text {a }}$ edición, reimpresión de 1996 , Ed. Civitas. 
pero que no deciden nada en particular. En palabras de Otto Mayer: "El acto administrativo es un acto de autoridad que emana de la Administración y que determina frente al súbdito lo que para él debe ser de Derecho en un caso concreto" 5 .

En consecuencia, "el concepto de acto-resolución administrativa permite aislar, dentro del conjunto de actuaciones de la Administración, unas medidas específicas y típicas, tanto frente a disposiciones y reglamentos, como frente a los actos de trámite, propuestas, informes, como frente a los contratos, así como frente a las actuaciones materiales o actos reales (derribo de un edificio declarado ruinoso; enseñanza en la Universidad, etc. $)^{6}$.

Y ello porque "el acto administrativo es el instrumento típico a través del cual la Administración, en ejercicio de las competencias que le atribuye el ordenamiento jurídico, manda, probíbe, autoriza, concede o deniega algo a los ciudadanos, crea relaciones jurídicas o adopta otras decisiones vinculantes"

En consecuencia, lo esencial del acto administrativo está en el ejercicio del poder público, cuyo ejercicio válido queda determinado por la competencia para su ejercicio, el cual permite que lo resuelto, es decir, la decisión de aplicación del ordenamiento jurídico, pueda imponerse de manera unilateral sobre los ciudadanos.

Para que esta decisión de aplicación del ordenamiento jurídico a un caso concreto sea eficaz, la LBPA en el inciso final del art. 3 le otorga una característica fundamental, tal es la presunción de legalidad. Ello viene a resolver la disputa doctrinaria que en un momento existió respecto, incluso, de la posibilidad de resistir el cumplimiento de actos que se estimaba ilegales. Con la entrada en vigor de la LBPA, los actos administrativos son legales mientras no se diga lo contrario por el juez o por la propia Administración del Estado en un procedimiento que tenga como resultado su invalidación (art. 53 LBPA). Esta presunción de legalidad del acto administrativo permite su ejecución desde luego por la propia Administración Pública en uso de sus poderes de autotutela.

Dichos poderes de autotutela son los que el inc. final del art. 3 denomina como imperio. Que los actos administrativos gocen de imperio supone que puedan imponerse aún en contra de la voluntad del ciudadano. Esto resulta lógico. Si se presume legal el acto administrativo, el paso siguiente será que ese acto que se dicta en ejercicio de una potestad pública, en definitiva del poder, tenga imperio, incluso por la fuerza. En consecuencia, frente a estas características tan poderosas del acto administrativo, los mecanismos de revisión y anulación del mismo cobran una extraordinaria importancia.

\section{LA ILEGAlidAd TOlERADA EN LA LEy N 19.880}

El acto administrativo se presume legal por el solo ministerio de la ley (art. 3 inc. final LBPA) y dicha presunción se ve reforzada, en los hechos, en aquellos casos en que

\footnotetext{
${ }^{5}$ Mayer, O. Derecho Administrativo Alemán, Tomo I, Ed. Depalma, Buenos Aires, 1949, p. 126.

${ }^{6}$ Gallego Anabitarte, A. y de Marcos Fernández, A., Derecho Administrativo, Materiales, Madrid, 1992, p. 317 .

${ }^{7}$ Gallego Anabitarte, A. y Menéndez Rexach, A., Acto y Procedimiento Administrativo, Ed. Marcial Pons, Madrid, 2001, p. 22.
} 
el acto se ha sometido al examen previo de legalidad, a través del trámite de toma de razón ante la Contraloría General de la República. Sin embargo, se trata de una presunción simplemente legal o iuris tantum, lo que permite que pueda ser desvirtuada a través de su impugnación en un procedimiento administrativo o en un procedimiento contencioso-administrativo. Evidentemente, la carga será de quien alega la ilegitimidad, sin embargo la impugnación y la tutela judicial efectiva harán posible controlar la actuación de la Administración del Estado, siendo una de sus consecuencias la posible extinción del acto administrativo por la ilegalidad de que adolece. Todo aparece claramente consagrado a nivel constitucional (art. 38) y legal (art. 2 Ley No 18.575 orgánica constitucional de bases generales de la Administración del Estado y art. 15 LBPA). Sin embargo, corresponde preguntarse si toda ilegalidad de que adolezca el acto administrativo conduce irremediablemente a su extinción, por nulidad o invalidación, o si, por el contrario, existiría una cierta graduación entre los diversos vicios de que adolecería el acto administrativo.

Una concepción irrestricta del principio de legalidad lleva a la conclusión de que cualquier vicio en un elemento del acto administrativo acarrearía una nulidad y por lo tanto la pérdida de eficacia y extinción del acto administrativo. En virtud de ella, cualquier vicio de que adolezca el acto administrativo lo lleva de forma inexorable a su extinción. Sin embargo, sólo una parte muy pequeña de la doctrina lo ha visto así y, lo que es más importante, en la realidad práctica nunca se ha entendido de esa manera el principio de legalidad, ni mucho menos se ha aplicado de esa forma. Y ello porque la regla no escrita, pero asumida, es que solamente deben tomarse en consideración las gravísimas infracciones legales para que se proceda a declarar la nulidad. En el Derecho comparado también se entiende de esa manera, en donde la regla general es la mera anulabilidad de los actos administrativos que infrinjan lo establecido en las normas jurídicas ${ }^{8}$.

La LBPA no es la excepción en esta materia y contiene un principio no expresado de permanencia o conservación de los actos jurídicos administrativos ${ }^{9}$. Es decir, si bien para la ley no resulta indiferente la ilegalidad del acto administrativo, no permitirá la extinción del mismo por cualquier vicio, sino que es exigible la concurrencia de ciertos requisitos de trascendencia para afectar la validez del acto.

\subsection{Vicios en el procedimiento}

El primer grupo de vicios tolerados son los de carácter procedimental. Así el art. 13 inc. 2 LBPA dispone que: "El vicio de procedimiento o de forma sólo afecta la validez del acto

${ }^{8}$ Bocanegra Sierra, R., Lecciones sobre el acto administrativo, Ed. Civitas, 2 a edición, Madrid, 2004, p. 165 .

9 Tal denominación ya había sido utilizada, incluso antes de la entrada en vigencia de la ley, por la doctrina, para referirse a los casos en que la ilegalidad del acto administrativo no conducía necesariamente a su anulación. Cfr. Marín, U., "Vigencia actual de la invalidación de los actos administrativos", en Revista de Derecho del Consejo de Defensa del Estado, No 2, año 2002. 
administrativo cuando recae en algún requisito esencial del mismo, sea por su naturaleza o por mandato del ordenamiento jurídico y genera perjuicio al interesado".

En consecuencia, a partir de la disposición transcrita puede concluirse que desde la perspectiva formal o procedimental, la legalidad del acto administrativo se pone en entredicho cuando el requisito es esencial por su propia naturaleza (ej. la notificación del acto; la recepción de pruebas; la emisión de un informe potestativo de otra Administración Pública) o porque el propio ordenamiento jurídico lo ha previsto así (ej. el quórum especial del concejo para la aprobación de un contrato que exceda el período alcaldicio, según lo dispone el art. 65 letra i) de la Ley Orgánica Constitucional de Municipalidades). A ello se agrega que, además, el vicio de forma o procedimiento debe causar perjuicio al interesado, aplicando el viejo adagio procesal "no hay nulidad sin perjuicio" 10.

\subsection{Convalidación del acto administrativo}

La convalidación comporta la verificación de un hecho jurídico o de una declaración administrativa en cuya virtud un acto administrativo que, en principio, podría haber sido anulado, adquiere plena validez. Ella puede producirse por dos vías:

- Transcurso del tiempo para interponer la acción o para invalidar de oficio o a petición de parte por la propia Administración Pública, que para este último caso es un plazo de dos años según lo dispone el art. 53 inc. $1^{\circ}$ LBPA.

- Declaración posterior en virtud de la cual se ratifica, confirma o subsana el acto administrativo. En este último sentido el art. 13 inc. $3^{\circ}$ LBPA dispone que: "La Administración podrá subsanar los vicios de que adolezcan los actos que emita, siempre que con ello no se afectaren intereses de terceros". Con lo que a partir de dicha disposición es posible concluir que en el ordenamiento jurídico administrativo chileno la Administración Pública está facultada para subsanar cualquier vicio que afecte al acto administrativo, con la única limitación de que dicha subsanación no afecte los intereses de terceros. Evidentemente, esta disposición debe ser entendida de forma alternativa a la potestad invalidatoria que la propia LBPA le entrega a la Administración.

El citado art. 13 inc. $3^{\circ}$ LBPA debe ser relacionado, además, con las facultades correctoras del procedimiento administrativo con que cuenta la Administración Pública. En efecto, el art. 10 inc. $2^{\circ}$ dispone que "Los interesados podrán, en todo momento, alegar defectos de tramitación, especialmente los que supongan paralización, infracción de los plazos señalados o la omisión de trámites que pueden ser subsanados antes de la resolución definitiva

${ }^{10}$ Se trata de una máxima aceptada plenamente desde antiguo por el Derecho procesal: "El moderno Derecho procesal tiende a respetar las formas procesales, per se, sin incurrir en formalismos. La infracción de la forma procesal debe producir un perjuicio a la parte que la alega, y por lo tanto, el acto procesal es válido si alcanza el fin previsto". Puppio, V., Teoría General del Proceso, $7^{\mathrm{a}}$ edición, Universidad Católica Andrés Bello, Caracas, 2008, p. 428. 
del asunto. Dichas alegaciones podrán dar lugar, si bubiere razones para ello, a la exigencia de la correspondiente responsabilidad disciplinaria". Por su parte, el art. 56, en el caso de los procedimientos administrativos de impugnación, esto es, los que tramitan recursos administrativos, dispone que "La autoridad correspondiente ordenará que se corrijan por la Administración o por el interesado, en su caso, los vicios que advierta en el procedimiento, fijando plazos para tal efecto".

En el Derecho comparado, la posibilidad de convalidar un acto administrativo viciado se dispone sólo respecto de aquellos actos administrativos anulables y no respecto de los viciados de nulidad plena o absoluta ${ }^{11}$.

Cabe preguntarse si la Administración puede subsanar cualquier vicio de su actuación, o la norma debe leerse en su contexto, esto es, referida sólo a los vicios procedimentales. Dado que la LBPA en el inciso $2^{\circ}$ del art. 13 ya señaló los requisitos para que el acto administrativo sea ilegítimo por vicios de procedimiento, y que el inc. $3^{\circ}$ discurre sobre vicios del acto administrativo y no del procedimiento administrativo, es plausible una interpretación extensiva de la norma, esto es, la que aplicando el principio de conservación del acto administrativo, permite la convalidación de otros vicios no formales o procedimentales.

Finalmente, se debe hacer una referencia a la conversión del acto administrativo. Esta procederá en aquellos casos en que un acto nulo o anulable que contiene elementos constitutivos de otro distinto producirá los efectos de éste. Sin embargo, dicha posibilidad no se encuentra reconocida de forma expresa en la LBPA.

\subsection{Notificación defectuosa}

El art. 47 de la LBPA dispone: "Notificación tácita. Aun cuando no bubiere sido practicada notificación alguna, o la que existiere fuere viciada, se entenderá el acto debidamente notificado si el interesado a quien afectare, hiciere cualquier gestión en el procedimiento, con posterioridad al acto, que suponga necesariamente su conocimiento, sin haber reclamado previamente de su falta o nulidad".

Los actos administrativos producen sus efectos obligatorios desde que se entienden perfeccionados y ello ocurre, habitualmente, con su notificación. Que el acto administrativo goce de eficacia jurídica quiere decir que este es obligatorio para aquellos que se encuentran comprendidos por el mismo, sean órganos de la Administración Pública, funcionarios o ciudadanos particulares destinatarios de la resolución.

Dicha eficacia jurídica es independiente del carácter válido o inválido que el acto administrativo detente, toda vez que, dada su presunción de legalidad, el acto

11 Tal es el caso de la ley española 30/92, de 26 de noviembre, de Régimen Jurídico de las Administraciones Públicas y del Procedimiento Administrativo Común, que en su art. 67 dispone: "Convalidación. 1. La Administración podrá convalidar los actos anulables, subsanando los vicios de que adolezcan. 2. El acto de convalidación producirá efecto desde su fecha, salvo lo dispuesto anteriormente para la retroactividad de los actos administrativos. 3. Si el vicio consistiera en incompetencia no determinante de nulidad, la convalidación podrá realizarse por el órgano competente cuando sea superior jerárquico del que dictó el acto viciado. 4. Si el vicio consistiese en la falta de alguna autorización, podrá ser convalidado el acto mediante el otorgamiento de la misma por el órgano competente". 
administrativo deberá ser cumplido mientras no sea anulado por el juez o invalidado por la propia Administración Pública de la cual emanó. El supuesto de la disposición transcrita permite mantener la eficacia del acto administrativo, no obstante carecer de uno de sus trámites esenciales y condicionantes de su eficacia, como lo es la notificación, es decir, que el acto administrativo no haya sido dado a conocer de acuerdo con la forma en que la ley establece.

De aplicarse la mentada teoría de la nulidad de Derecho público, habrá que concluir que un acto administrativo en que falta o se ha realizado de manera irregular la notificación adolece de un vicio de forma (en la forma que prescriba la ley, exige el art. 7 inc. $1^{\circ}$ parte final CPR). Sin embargo, la LBPA de manera pragmática reconoce la posibilidad de que no obstante no haberse producido la notificación legal, el acto administrativo sí fue conocido por el destinatario, dotándolo de eficacia cuando éste ha realizado una gestión con posterioridad al acto administrativo que suponga necesariamente su conocimiento, excluyéndose, eso sí, los casos en que dicha gestión hubiere sido precisamente el reclamo de la falta de notificación o la nulidad del mismo acto administrativo. Precisamente, esta última expresión, del art. $47 \mathrm{LBPA}$, en que se alude al reclamo de la nulidad del acto administrativo por su falta o errónea notificación, es demostrativa de que dicho vicio es de aquellos que son suficientes para la declaración de nulidad del acto.

Sin embargo, el legislador presume la conformidad con la manera en que se dio a conocer la actuación, a través de esta regla de notificación tácita.

\subsection{Rectificación de errores de becho, aritméticos o materiales}

El art. 62 LBPA dispone lo siguiente: "Aclaración del acto. En cualquier momento, la autoridad administrativa que bubiere dictado una decisión que ponga término a un procedimiento podrá, de oficio o a petición del interesado, aclarar los puntos dudosos u obscuros y rectificar los errores de copia, de referencia de cálculos numéricos y, en general, los puramente materiales o de hechos que aparecieren de manifiesto en el acto administrativo".

La disposición en comento hace una distinción entre dos situaciones:

- Errores materiales: se trata de defectos en la confección o escrituración del acto administrativo los que son fácilmente identificables y subsanables.

- Aclaración de puntos dudosos u obscuros: los cuales hacen difícil la inteligencia de la decisión administrativa. Sin embargo, a propósito de dicha aclaración, la Administración Pública no podría innovar en su resolución, alterando el contenido del acto administrativo.

En virtud de esta disposición se habilita a la Administración para perfeccionar un acto administrativo que adolece de errores de tipo material, pero que no inciden en la resolución o decisión que da contenido al acto. En consecuencia, para proceder a la reparación del acto administrativo la Administración Pública deberá basarse en los elementos que constan en el mismo expediente administrativo y que permiten concluir que la resolución contiene un error aritmético o material. 
Para el ejercicio de dicha potestad no existe plazo - a diferencia del límite temporal de dos años para el ejercicio de la potestad invalidatoria-, toda vez que ella no supone una variación de lo decidido, sino, por el contrario, una aclaración o perfeccionamiento del acto administrativo.

La presencia de esta clase de errores en la actuación no producirá consecuencia jurídica alguna para la Administración Pública de la cual emanó el acto administrativo. Sin embargo, cada vez que la Administración ejerza esta facultad de enmendar o aclarar el acto administrativo deberá hacerlo en una nueva resolución o acto administrativo, sin sustituir el acto administrativo, entendiéndose que lo decidido se mantiene inalterado en el acto original.

Evidentemente el problema de la facultad del art. 62 LBPA radica en la determinación de los límites de este poder de reparación del acto administrativo. Si bien la ley no entrega criterios específicos, habría que concluir que no será posible reparar el acto si éste adolece de vicios de ilegalidad en la resolución. En tal caso, lo que procederá es el ejercicio de la potestad invalidatoria. Asimismo, no podrá la Administración por esta vía encubrir una revocación del acto administrativo, evadiendo así los límites que dispone para la misma el art. 61 LBPA.

\section{El probable REtroceso del RECURSO de PROTECCIÓN COMO VÍA DE CONTROL CONTENCIOSO ADMINISTRATIVO}

No corresponde analizar aquí la conveniencia o no de la utilización del recurso de protección como mecanismo paliativo frente a la inexistencia de una jurisdicción contencioso administrativa de carácter general y partiremos de la base de que "el recurso de protección se ha convertido efectivamente en el proceso contencioso administrativo por excelencia en nuestro derecho"12.

El auto acordado sobre tramitación y fallo del recurso de protección de las garantías constitucionales (publicado en el Diario Oficial de 27 de junio de 1992) fue modificado con fecha 8 de junio de 2007, sustituyéndose entre otros el inc. $2^{\circ}$ del numeral 2 por el siguiente: "Presentado el recurso, el Tribunal examinará en cuenta si ha sido interpuesto en tiempo y si se mencionan hechos que puedan constituir la vulneración de garantías de las indicadas en el artículo 20 de la Constitución Política de la República. Si su presentación es extemporánea o no se señalan bechos que puedan constituir vulneración a garantías de las mencionadas en la referida disposición constitucional, lo declarará inadmisible desde luego por resolución fundada, la que sólo será susceptible del recurso de reposición ante el mismo tribunal, el que deberá interponerse dentro de tercero día". Como se sabe, la disposición transcrita establece el examen de admisibilidad de las acciones de protección interpuestas, el cual en su versión original se refería a la interposición

${ }^{12}$ Ferrada Bórquez, J. C., "El recurso de protección como mecanismo de control contencioso administrativo", en Justicia Administrativa, Juan Carlos Ferrada Bórquez, coordinador, Ed. LexisNexis, Santiago, 2005, p. 133. 
en tiempo y a si contaba con fundamentos suficientes para acogerlo a tramitación ${ }^{13}$. Es precisamente esta segunda exigencia la que ha sido cambiada, toda vez que ahora se pasa de la exigencia de fundamentación suficiente a exigir que se mencionen hechos que puedan constituir vulneración de las garantías de aquellas indicadas en el art. 20 CPR.

La razón de la modificación del auto acordado, que incluye la duplicación del plazo de interposición pasando de 15 a 30 días corridos, se encuentra en un afán garantista de la Corte Suprema, probablemente motivado por la nueva facultad del Tribunal Constitucional de resolver sobre la constitucionalidad de los autos acordados dictados por la Corte Suprema (art. $93 \mathrm{~N}^{\circ} 2 \mathrm{CPR}$ ). Esta finalidad, en principio, se logra, toda vez que se sustituye un examen de la fundamentación suficiente, por uno aparentemente más sencillo consistente sólo en mencionar hechos que puedan constituir vulneración a los derechos constitucionales enumerados en el art. $20^{14}$.

No obstante lo anterior, la modificación experimentada está produciendo un efecto contrario respecto de la revisión por esta vía de los actos administrativos. No existe jurisprudencia conocida acerca del examen de admisibilidad del recurso de protección, toda vez que ésta es resuelta a través de una sentencia interlocutoria respecto de la que difícilmente se tiene acceso. Sin embargo, existe la percepción de que el criterio si ya era muy dispar respecto de la forma en que se interpretaba la exigencia de fundamentación suficiente, hoy día existe una gran incertidumbre acerca de lo que debe entenderse por "bechos que puedan constituir la vulneración de garantías de las indicadas en el artículo 20". De lo que sí existe jurisprudencia es respecto del carácter de hecho o no que pudiere tener un acto administrativo impugnado por la vía del recurso de protección. Así por ejemplo, la sentencia de la Corte Suprema de 12 de agosto de 2002 (caso Valenzuela Silva con Comisión Nacional del Medio Ambiente), a propósito de una resolución de calificación ambiental, se considera que dicho acto administrativo no es susceptible de causar una afectación de derechos constitucionales, toda vez que un acto administrativo no puede

${ }^{13}$ Al respecto, se puede sostener lo afirmado por Nogueira Alcalá que señala que "Dicha normativa tuvo el objetivo de detener la inflación de recursos de protección presentados ante las Cortes de Apelaciones, logrando su finalidad, poniendo fin a recursos de protección claramente mal estructurados o no referentes a derechos fundamentales, pero también estableció un margen apreciable de discrecionalidad de las cortes de apelaciones para apreciar la "manifiesta" falta de fundamento del recurso, la que ha sido entendida como falencias tanto de forma como de fondo, el que ha sido estrictamente aplicado, convirtiendo al recurso en una acción constitucional casi marginal, donde muchas veces es muy difícil sobrepasar el control de admisibilidad aplicado discrecionalmente por el tribunal respectivo, sin que existan criterios uniformes de general aplicación, cuando ya estamos cerca de una década de su implementación normativa”, Nogueira Alcalá, H., "El Recurso de Protección en el Contexto del Amparo de los Derechos Fundamentales Latinoamericano e Interamericano", en Ius et Praxis, volumen $13 \mathrm{~N}^{\circ} 1$, 2007, pp. 75-134.

${ }^{14}$ Debe tenerse en cuenta que la doctrina ya había criticado la introducción del examen de admisibilidad de la acción de protección, afirmándose incluso que dicho examen adolece de nulidad de Derecho Público. En tal sentido, Andrades Rivas, E., "Comentarios al nuevo auto acordado sobre tramitación del Recurso de Protección”, en Revista Chilena de Derecho, Número Especial, año 1998, p. 123. 
causar contaminación y que lo amparado por el recurso de protección son derechos afectados actualmente y no por proyectos que se producirán en el futuro ${ }^{15}$.

En consecuencia, para la citada jurisprudencia el acto administrativo impugnado no es un acto de aquellos a que se refiere el art. 20 CPR contra los que procede el recurso de protección, con lo que con menor razón, aplicando el mismo razonamiento, constituirá un hecho que pueda constituir un afectación a alguna de las garantías amparadas por esta vía. En realidad, la innovación del auto acordado va en contra del propio texto constitucional, ya que el art. 20 hace procedente el recurso de protección frente a actos que afecten los derechos que en la norma se enumeran. La expresión acto utilizada en la CPR es comprensiva de actos jurídicos, como el acto administrativo, y de actos materiales, es decir hechos, por lo que es dudosa la constitucionalidad del auto acordado en orden a exigir la mención de hechos que puedan afectar a los derechos fundamentales.

\section{LA JURISPRUDENCIA ACTUAL EN MATERIA DE NULIDAD DEL}

\section{ACTO ADMINISTRATIVO}

La evolución de la jurisprudencia en materia de nulidad del acto administrativo lleva a preguntarse qué queda de las características que originalmente se le habían atribuido, esto es, que se trata de una nulidad ipso iure, es insanable y, por tanto, imprescriptible ${ }^{16}$. Como se verá en el presente apartado, la evolución de la jurisprudencia no sólo es ilustrativa respecto del retroceso de la señalada teoría de la nulidad de Derecho público,

${ }^{15}$ En particular, se señala: “ $4^{\circ}$ ) Que resulta fácil advertir de la lectura y análisis tanto del escrito que contiene el recurso como de los antecedentes reunidos, que el fundamento del mismo no es la perpetración de algún acto u omisión arbitrario o ilegal que prive, perturbe o atente contra el ejercicio de la referida garantía constitucional invocada, ya que lo que en verdad se cuestiona es la apreciación u opinión contenida en una Resolución que se limita a calificar favorablemente un "proyecto" de carácter industrial; autorización o informe que constituye tan sólo uno de los eslabones que deben preceder a un proyecto de esta naturaleza. Lo cierto es que la impugnación se basa en el temor de que el funcionamiento de la industria pueda producir contaminación ambiental, lo que necesariamente constituye una situación futura.

Esto es, el recurso persigue una finalidad impropia de su naturaleza cautelar, puesto que lo que pretende es impedir la concreción del proyecto industrial de que se trata, por la vía de impugnar una resolución que constituye solamente uno de los requisitos para que aquel pueda concretarse, imputándole la calidad de ilegal, arbitraria y violatoria de una garantía constitucional. Dicha garantía no puede resultar vulnerada por el informe o resolución impugnada, pues por su propia naturaleza, este acto no es susceptible de producir la situación que dicho principio constitucional intenta precaver, desde que se trata de la valoración técnica que hizo una autoridad, esto es, un acto administrativo de opinión y no un acto de resultado material que haya originado contaminación en el medio ambiente o, aun, que pueda producirla;

$5^{\circ}$ Que, en efecto, el acto que se impugne mediante la presente acción cautelar debe, derechamente, producir contaminación, de tal suerte que en ese caso, se ha de reclamar en contra del directamente responsable, lo que en la especie no es así, porque la protección se ha dirigido, como quedó explicado precedentemente, respecto de un acto administrativo, que, en lo tocante a la contaminación, ha de ser estimado como inocuo, independientemente de que se comparta o no la opinión que éste contiene;

$9^{\circ}$ Q Que, se colige de lo dicho, que en la especie no sólo no existe acto ilegal o arbitrario respecto del cual se pueda intentar cautela, sino que no existe acto ninguno, por lo que el recurso carece de fundamentos de becho y de derecho".

16 Soto Kloss, E., "La nulidad de Derecho público en el derecho chileno", Revista de Derecho Público,

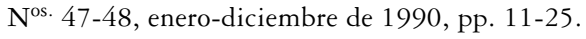


sino que además, y lo que es más grave, del retroceso en la construcción y desarrollo del Estado de Derecho en general. Con esto no se quiere afirmar que la nulidad de Derecho público, así como fue originalmente concebida, sea realmente la solución para enfrentar la revisión judicial de los actos administrativos, pero constituía una solución que en un momento permitió hacer frente a la impunidad administrativa. Asimismo, es probable que considerado en el largo plazo, esta etapa de la jurisprudencia de los tribunales superiores y en particular de la Corte Suprema sirva para incentivar la solución legislativa a la falta de un proceso o bien una jurisdicción contencioso administrativa. Sin embargo, por lo pronto será necesario buscar y encontrar otras soluciones frente al reducido ámbito de la nulidad de Derecho público.

\subsection{Prescriptibilidad de la responsabilidad extracontractual}

Uno de los aspectos de la jurisprudencia de la Corte Suprema que se ha mantenido constante durante el último tiempo es el de la distinción entre la acción de nulidad y las de contenido patrimonial. Producto de esta separación se entiende que las reglas de prescripción del Código Civil, en virtud de lo dispuesto en su art. 2497, resultarán aplicables a las acciones de contenido patrimonial. El efecto práctico de esta jurisprudencia radica en que en todos aquellos casos -que son la mayoría- en que se intenta la nulidad de una actuación de la Administración, inmediatamente, y como consecuencia de ella, se pide al tribunal que se declare el derecho a la indemnización de perjuicios o en menor grado se ejerce otra acción patrimonial. En estricto rigor, se trataba de acciones declarativas de derechos y no de impugnación o de nulidad.

Sin embargo, el problema de esta doctrina radica en dos aspectos, en primer lugar la distinción entre acciones de nulidad (stricto sensu) y de plena jurisdicción (en que se revisa la legalidad y la declaración de derechos subjetivos, de ahí su denominación) no tiene asidero en el ordenamiento jurídico chileno. Como consecuencia de lo anterior, es que la nulidad del acto administrativo, en un juicio de nulidad de Derecho público, es la causa de la indemnización, ya que el acto ilegal es, en principio, el acto que ocasiona el daño.

El fallo que marca el inicio de esta distinción es la sentencia de la Corte Suprema de 27 de noviembre de 2000 recaída en el caso Aedo con Fisco. El cual señalaba en su parte medular lo siguiente:

Considerando $7^{\circ}$ parte final: "La doctrina en general ha considerado que esta nulidad, por las características que presenta y el modo como está concebida en el ordenamiento básico de la institucionalidad, opera de pleno derecho de modo que solicitado al tribunal, éste, al asentar los elementos de becho que representan una invasión de potestades, no tiene otra función que reafirmarla, constatando su existencia y siendo así, no puede aplicársele las normas generales de derecho privado sobre prescripción de las acciones. Asimismo, al no existir norma alguna que consagre lo contrario, cabe llegar a la conclusión que esta nulidad es imprescriptible, debido a que no es posible aplicar esta causal de extinción de las acciones y derechos sin una norma legal que la establezca". 
De lo que se desprende que la nulidad de Derecho público es imprescriptible porque no existe una norma expresa de prescripción (cosa discutible atendido el tenor amplio del art. 2497 del Código Civil) y no por el tenor del art. 7 inc. final CPR, como afirmaba la doctrina que sustenta la imprescriptibilidad.

Más adelante, la misma sentencia señala:" $8^{\circ}$ ) Que, por el contrario, las acciones reivindicatoria y de indemnización de perjuicios que también se han deducido por la actora, como derivadas de la anterior de nulidad de derecho público, y referidas en los capítulos de casación primero y último, son de evidente contenido patrimonial, pues se refieren a los aspectos materiales y monetarios que pretende obtener la actora en virtud de la declaración de nulidad que busca. De lo anterior se deriva que su destino se condiciona de lleno a los plazos de prescripción establecidos al respecto por el Código Civil. En este sentido cabe hacer presente que la propia actora condiciona $y$ ampara estas pretensiones en diversas normas de este cuerpo legal;

$\left.9^{\circ}\right)$ Que siendo entonces inconcuso el situar las acciones patrimoniales también deducidas en el ámbito que les es propio, cual es el del derecho privado y común, debe enseguida examinarse si es efectiva la alegación de la demandada en orden a que ellas se encuentran prescritas, en conformidad con lo que al efecto establece el Código Civil. Al respecto debe recordarse que sus artículos 2514 y 2515 disponen que las acciones se extinguen por el solo transcurso del tiempo, bastando para ello el lapso de cinco años para las acciones ordinarias".

Esta doctrina también había sido aplicada en el sentido inverso, es decir, en aquellos casos en que era la Administración la que demandaba la nulidad de una actuación generadora de derechos, limitándose los efectos patrimoniales (restitución de dinero) por aplicación de los plazos de prescripción. Así, la sentencia de la Corte Suprema de 30 de agosto de 2007 (caso INP con Cuello) señalaba: " $17^{\circ}$ Sin embargo, bien distinta es la declaración de nulidad de Derecho Público del acto de la Administración que se priva de valor con el pronunciamiento judicial, del alcance que ha de dársele en relación con los efectos de carácter patrimonial que produjo el acto mientras perduró su eficacia y que en el caso de que se trata, incide en las acciones ejercidas contra los demandados por el Instituto de Normalización Previsional, a fin de obtener la restitución de los dineros que, por concepto de pensiones de invalidez e indemnización por años de servicio, se les pagó en razón de los decretos afectados por la declaración de nulidad consabida, porque atendida la naturaleza pecuniaria que revisten las prestaciones consiguientes, quedan sujetas estas acciones, en lo que concierne a la institución de la prescripción extintivas, a las normas que consagra el Código Civil".

Tampoco para la Corte Suprema es problemático escindir las dos acciones ejercidas, señalando que " $18^{\circ}$ la relación de necesaria interdependencia que existe entre la acción de nulidad de derecho público y las acciones de naturaleza patrimonial que persiguen la restitución de los dineros, si bien tienen un antecedente común, en los términos que se ha planteado por los dos recursos de casación, no se opone a que estén sometidas a estatutos jurídicos diferentes como se ha establecido, de suerte que la primera de ellas pueda subsistir más allá de los plazos de prescripción o de caducidad que rigen respecto de las segundas".

Sin embargo, en el último tiempo, y curiosamente respecto de casos similares al anteriormente expuesto, esto es, en que se trata de un organismo de la Administración del Estado que demanda la nulidad acompañada de una restitución de montos pagados, 
la Corte Suprema ha variado su doctrina señalando que procede la aplicación del art. 1687 del Codigo Civil. Así por ejemplo en el asunto INP con Godoy Hernández, en sentencia de fecha 30 de marzo de $2009^{17}$, la Corte Suprema señala que la acción de restitución de los dineros pagados por concepto de pensiones e indemnizaciones es una acción que "queda sujeta a la regulación normativa que, en lo tocante a los efectos de la declaración de nulidad de los actos jurídicos, se contempla en el Código Civil" (Considerando 14²). Y más adelante señala que "a este respecto, el artículo 1687 de dicho cuerpo legal en su inciso $1^{\circ}$ dispone que "La nulidad pronunciada en sentencia que tiene fuerza de cosa juzgada, da a las partes derecho para ser restituidas al mismo estado en que se hallaría si no bubiese existido el acto o contrato nulo". De acuerdo con este precepto, entonces, la nulidad judicialmente declarada posee un definido efecto retroactivo, determinando que las cosas vuelvan al mismo estado o situación en que se encontraban antes de celebrarse el acto invalidado, cuyas consecuencias o efectos jurídicos se extinguen" (Considerando $15^{\circ}$ ). Con mayor claridad, si cabe, en el asunto INP con Muñoz Candia, de fecha 29 de octubre de 2009, la Corte Suprema señaló que: "resultando imperioso declarar la nulidad del acto administrativo de que se trata, con el consiguiente efecto de retrotraerse las cosas al estado en que se hallarian si aquel no bubiera existido, según se prevé en el artículo 1687 del Código Civil-aplicable al régimen de las acciones restitutorias subsiguientes al pronunciamiento anulatorio-procede acoger la pretensión de la actora en orden a que se le restituyan por el demandado los dineros correspondientes a las prestaciones previsionales indebidamente percibidas, en virtud del acto írito".

\subsection{Distinción entre acciones de nulidad y de plena jurisdicción}

A pesar de que en el Derecho administrativo chileno no se distingue entre acciones de nulidad y plena jurisdicción (supra 6.1), se trata de una clasificación que ha ido ganando terreno en la jurisprudencia del máximo tribunal. Así en una serie de fallos de la Corte Suprema se hace esta distinción, es decir, entre acciones ejercidas sólo para obtener la nulidad del acto administrativo y acciones que además persiguen la declaración de un derecho. Así por ejemplo, en sentencia de fecha 28 de junio de 2007 (caso Eyzaguirre con Fisco ${ }^{18}$, se señala lo siguiente: " $10^{\circ}$ ) Que el análisis del recurso, habida cuenta

${ }^{17}$ Sin duda, el fallo en comento constituye un cambio en la tendencia de la jurisprudencia, ya que justo un mes antes, en sentencia de fecha 29 de enero de 2009 (asunto INP con Zamora Luis y otros), la Corte Suprema había reiterado la doctrina señalando: "Que, en cambio, las acciones ejercidas en contra de los demandados por el Instituto de Normalización Previsional con miras a obtener de éste la restitución de los dineros que, por concepto de pensiones de invalidez e indemnización por años de servicio, les fueron pagados en virtud de los decretos afectados por la declaración de nulidad de derecho público, dada su evidente naturaleza patrimonial - en cuanto se refieren a prestaciones de valor económico- quedan sujetas a la regulación normativa que, en lo tocante a la prescripción extintiva, se contemplan en el Código Civil" (considerando $15^{\circ}$ ).

${ }^{18}$ Existe un conjunto de sentencias de la Corte Suprema que utilizan esta misma distinción, tal como afirma en su sentencia de 1 de julio de 2009 (caso INP con Espinoza Loredo), en que se dice expresamente que: "Noveno: Que el análisis del recurso conduce a dejar formulada, como ha hecho esta Corte en anteriores fallos sobre la misma materia, una necesaria distinción entre las acciones encaminadas únicamente a conseguir la nulidad de un acto administrativo y aquéllas que miran a la obtención de algún derecho a favor de un particular". 
del contenido complejo de la demanda planteada en estos antecedentes, según se dejó constancia en el basamento octavo anteprecedente, conduce a dejar formulada una necesaria distinción entre las acciones encaminadas únicamente a conseguir la nulidad de un acto administrativo y aquéllas que miran a la obtención de algún derecho en favor de un particular. Las primeras pueden interponerse por cualquiera que tenga algún interés en ello, presentan la particularidad de hacer desaparecer el acto administrativo con efectos generales, "erga omnes y requieren de una ley expresa que las consagre, como ocurre con el artículo 140 de la Ley $N^{\circ}$ 18.695, Orgánica Constitucional de $M$ unicipalidades, que instituye el reclamo de ilegalidad contra las resoluciones u omisiones ilegales de los órganos municipales. En cambio, las segundas presentan la característica de ser declarativas de derechos, perteneciendo a esta clase la que se ha entablado en autos, en que la nulidad del acto administrativo se persigue con el propósito de obtener la declaración de un derecho en favor del demandante, la indemnización de perjuicios, en lo específico;

$11^{\circ}$ ) Que estas acciones declarativas de derechos, de claro contenido. patrimonial, producen efectos relativos, limitados al juicio en que se pronuncia la nulidad y se encuentran sometidos, en lo concerniente a la prescripción, a las reglas generales sobre dicho instituto, contempladas en el Código Civil, entre otras, a las disposiciones de sus artículos 2332, 2497, 2514 y 2515".

Lo primero que llama la atención de la sentencia citada es la distinción de acciones entre la de nulidad propiamente tal y la de plena jurisdicción, la cual en la especie denomina como declarativa de derechos, en este caso, el derecho a la indemnización de perjuicios.

Dentro de las características que se le endilgan a la acción de nulidad, hay dos de ellas que tradicionalmente se atribuyen a estas acciones: que producen efectos erga omnes, es decir, el acto administrativo desaparece para todos; y que pueden ser intentadas por cualquier persona, es decir, acción popular. Sin embargo, un tanto al pasar, el tribunal les atribuye una tercera característica: "requieren de una ley expresa que las consagre, como ocurre con el artículo 140 de la Ley $N^{0} 18.695$, Orgánica Constitucional de Municipalidades". Si esto es realmente así, quiere decir, ni más ni menos, que para intentar sólo la nulidad del acto administrativo, en cuanto acción de impugnación, se requiere que el medio procesal, es decir, la acción, esté prevista expresamente en la ley. En consecuencia, no sería suficiente para impugnar el acto administrativo la acción de nulidad de Derecho público del art. 7 inc. $3^{\circ} \mathrm{CPR}$ ya que la acción de nulidad en contra de actos administrativos ilegales debe estar expresamente establecida en la ley, con lo que a falta de ley que lo establezca, no cabría acción alguna. Esta interpretación desconocería la relación entre acciones de nulidad prevista en la ley y la nulidad de Derecho Público, el cual entiende que esta última acción será procedente al menos si el acto administrativo se encontrase en alguna de las causales del art. 7 inc. $1^{\circ}$.

Es casi anecdótico, pero para ilustrar su razonamiento el tribunal cita el art. 140 de la Ley $\mathrm{N}^{\circ}$ 18.695, Orgánica Constitucional de Municipalidades (aunque en realidad es el art. 141). Sin embargo, el ejemplo utilizado es erróneo, pues precisamente en el caso del reclamo de ilegalidad municipal, dentro de los poderes de la Corte de Apelaciones, además de anular, está el de declarar el derecho a la indemnización de perjuicios. Es decir, se trata de una acción típica de plena jurisdicción o declarativa, en el concepto de la Corte Suprema y no una acción puramente anulatoria. 


\subsection{Remisión a las normas del Código Civil}

La Corte Suprema no tiene ningún problema en llenar las lagunas que plantea el Derecho administrativo mediante la remisión a normas expresas del Código Civil. Así ocurre, especialmente, con la aplicación de las normas sobre nulidad, responsabilidad y, especialmente, prescripción (art. 1687, artículos 2314 y siguientes, art. 2497 , etc.) ${ }^{19}$.

Ya he manifestado en otra parte mi posición favorable a este respecto ${ }^{20}$. A lo anterior, incluso he invocado lo que ocurre en el Derecho administrativo comparado, en particular el alemán, en que no existe cuestionamiento para llenar las lagunas normativas con normas de Derecho común ${ }^{21}$. Ello se funda en la posibilidad de encontrar la base de los principios generales del Derecho en el Código Civil y en la aplicación por analogía de normas privadas en el ámbito administrativo ${ }^{22}$. Esta posición no es compartida, en general, por la doctrina administrativista, señalándose que "cada disciplina autónoma, conforma su sistema de instituciones y principios, que ayudan a esa autointegración, y la única argamasa son los principios jurídicos, pero no la burda práctica de trasladar, sin tamiz alguno, leyes desde un sistema a otro, sin percibir la incoberencia que puede significar ese arrastre desde disciplinas que no sólo son distintas en cuanto a su esencia a su célula más básica: la relación jurídica" 23 . Sin desconocer el valor dogmático de los argumentos expuestos en la cita -que en la práctica implican la autarquía del ordenamiento jurídico administrativo- me parece que en el estado actual de la disciplina no es posible sostener dicha postura sin chocar con lo que la realidad nos enseña. Es precisamente la aplicación de los preceptos del Código Civil la que ha salvado la evolución del Derecho administrativo frente a la desidia y desinterés en desarrollar legislativamente sus instituciones. Si no fuera posible la aplicación de las normas del Código Civil probablemente el Estado todavía sería irresponsable frente a los daños que infrinja a los particulares y, como veremos en el próximo numeral, es la aplicación de las disposiciones del Código Civil una

${ }^{19}$ En la citada sentencia de fecha 28 de junio de 2007 (caso Eyzaguirre con Fisco), así como en una serie de fallos, anteriores y actuales, la Corte Suprema expresó: " $12^{\circ}$ ) Que conviene tener presente en este punto que, si bien las personas jurídicas de derecho público, como el Estado Fisco, por su propia naturaleza, se rigen por leyes y reglamentos especiales y están excluidas del régimen del derecho común, según el artículo 547 inciso $2^{\circ}$ del Código Civil, este mismo cuerpo normativo establece una excepción a tal principio en el precitado artículo 2497, al establecer que "las reglas relativas a la prescripción se aplican igualmente a favor y en contra del Estado, de las iglesias, de las municipalidades, de los establecimientos y corporaciones nacionales...; 13 ${ }^{\circ}$ ) Que la prescripción extintiva de las acciones judiciales exige solamente cierto lapso de tiempo, durante el cual no hayan sido ejercidas (artículo 2514 del Código Civil); plazo que es en general de cinco años para las acciones ordinarias (artículo 2515 del mismo Código) y de cuatro años para las acciones encaminadas a hacer efectiva la responsabilidad extracontractual (artículo 2332)".

${ }^{20}$ Bermúdez Soto, J., "El principio de legalidad y la nulidad de Derecho Público en la Constitución Política. Fundamentos para la aplicación de una solución de Derecho Común”, en Revista de Derecho Público, Volumen 70, año 2008, pp. 273-285.

21 En particular respecto de las normas sobre prescripción, Guckelberger, A., Die Verjährung im Öffentlichen Recht, Ed. Mohr-Siebeck, Tübingen, 2004, p. 294.

${ }^{22}$ Cfr. Maurer, H., Verwaltungsrecht, $12^{\mathrm{a}}$ edición, Ed. Beck, Munich, 1999, páginas 54 y ss.

${ }^{23}$ Vergara Blanco, A., "Derecho administrativo y supuesta supletoriedad general del Código Civil", en Revista de Derecho Administrativo, 2009, No 3, p. 61. 
de las pocas soluciones positivas frente a la imposibilidad de anular los actos administrativos contrarios a Derecho.

\subsection{Causales taxativas de nulidad}

Un problema recurrente es el de determinar las causales de nulidad de Derecho público, las cuales, en principio, son las del art. 7 CPR. En el fallo de la Corte Suprema asunto "Camacho Santibáñez con Fisco de Chile", de fecha 28 de junio de 2006, el máximo tribunal vuelve sobre el tema de las causales de nulidad de Derecho Público, señalando en su considerando décimo que: "Dicha acción (de nulidad de Derecho Público) se justifica, cuando un acto ha sido dictado con omisión de la investidura regular que exige la ley para el nombramiento de la autoridad administrativa, o cuando ésta aun teniendo título de tal, dicta el acto fuera de la competencia que le ha fijado el constituyente o el legislador, o sea, cuando ha excedido el marco de autorización legal, que le otorga límites en su actuación con relación a la materia, jerarquía y el territorio y, finalmente, el acto carece de eficiencia absoluta por falta de formalidades inherentes para la validez intrínseca del acto que se reputa irregular".

Es decir, el tribunal es de la opinión de que las causales que habilitan la acción de nulidad de Derecho público son sólo aquellas contenidas en la norma del artículo 7, y específicamente aquellas del inciso $1^{\circ}$.

Más adelante, en el considerando decimocuarto el máximo tribunal se refiere a la ilegalidad de que se moteja el acto impugnado: "Sólo es base de la presente nulidad de Derecho público, la violación de la ley, lo que según la doctrina se refiere a la legalidad interna del acto, es decir, se trata del quebrantamiento del ordenamiento jurídico que descarta las vulneraciones de incompetencia, investidura y forma y, por esta sola circunstancia, aparte que tal infracción en sentido estricto no es sancionable con la nulidad de derecho público, ni tampoco se balla contenida en el artículo 7 de la Constitución, que establece perentoriamente la nulidad en los supuestos primeramente anotados y que especifica esta última norma, cuestión que a lo más podrá quedar comprendida dentro de las ilegalidades que señala el artículo 6 de la Carta Fundamental, norma que sólo entrega al legislador establecer las sanciones y responsabilidades que genere la infracción de este último precepto".

En consecuencia, la Corte Suprema es de la opinión de que no es causal de nulidad de Derecho público el vicio en el objeto o ilegalidad sustantiva del acto administrativo, y que el quebrantamiento del ordenamiento jurídico por el acto impugnado, cuando no incurre en incompetencia, falta de investidura, ni de forma, no será impugnable por la vía de esta acción. Y ello porque la sanción a la infracción a la legalidad material está en el artículo 6 CPR y esta norma remite su sanción a la ley y no al art. 7 CPR.

En el mismo considerando decimocuarto se confirma la conclusión anterior, al señalarse que: "Si la base de la demanda es la acción de nulidad de Derecho público, deberá estarse al quebrantamiento de los componentes de juridicidad a que se refiere el artículo 7 del Estatuto Constitucional, por lo que por esta sola circunstancia no ha sido posible acoger la demanda...". En la citada jurisprudencia se constata una interpretación estricta de las causales de nulidad de Derecho público. Ello no resulta objetable si se tiene en cuenta que se trata 
de una sanción de Derecho estricto, la que no puede ser interpretada con laxitud ${ }^{24}$. A ello se suma que hoy en día, en virtud del artículo 3 inciso final de la LBPA, los actos administrativos gozan de una presunción de legalidad, y que en dicho cuerpo normativo se contiene un principio de conservación de la actuación administrativa.

Sin embargo, la interpretación expuesta conlleva un grave peligro, esto es que deja sin posibilidades de impugnación a la situación más común de actuación viciada, tal es que el acto administrativo se dicte adoleciendo de una ilegalidad material o en su objeto, producto de la errada aplicación del ordenamiento jurídico. Frente a tales supuestos, según la Corte Suprema, no procede la acción de nulidad de Derecho público. Por lo tanto, la duda se plantea respecto de aquellos actos que cumpliendo estos requisitos formales incurren en una ilegalidad sustantiva, de fondo (por ejemplo, un acto administrativo dictado con desviación de poder o con exceso de poder).

Esta doctrina ha ido ganando espacio en los tribunales de justicia. Así en la sentencia de la Corte Suprema de 30 de agosto de 2007 (caso INP con Cuello), el considerando $15^{\circ}$ señala que "de conformidad con este último precepto constitucional, la validez de las actuaciones de los órganos del Estado queda supeditada a la concurrencia, en forma copulativa, de tres presupuestos que son fundamentales, cuales son: la investidura regular del agente; que su actividad se desarrolle dentro del ámbito de su competencia, y que se ajuste a la forma prescrita en la ley". Es decir, enumera las causales taxativas de nulidad de Derecho público, sin que se incluya entre ellas la ilegalidad en el objeto o materia del acto administrativo, que se traduce en los vicios de abuso de poder y desviación de poder. Similar doctrina ha aplicado la Corte de Apelaciones de Santiago, la que en fallo de fecha 5 de julio de 2007 (asunto Abrego Diamantti con INP), ha resuelto lo siguiente: "8: Que como ha sido resuelto por la Excma. Corte Suprema en materias análogas, tal supuesta infracción en sentido estricto no es sancionable con la nulidad de derecho público ni se halla contenida en el artículo $7^{\circ}$ de la Constitución, que establece perentoriamente la nulidad en los supuestos de investidura regular, competencia, requisitos externos o abuso en el ejercicio de las potestades. Teóricamente, podría quedar comprendida en las ilegalidades que señala el artículo $6^{\circ}$ de la Constitución, que entrega a la ley las sanciones y responsabilidades que genere su infracción".

No obstante lo anterior, la Corte Suprema ha dado pie a una extensión de las causales, al menos incorporando dentro de los requisitos formales al motivo o fundamento del acto administrativo. Así en la citada sentencia de la Corte Suprema "INP con Cuello" en que se afirma que "por consiguiente, cuando actos de la Administración, como los decretos del ente previsional a que se refiere la controversia de autos, no se ban ajustado a la forma prescrita por

${ }^{24}$ En la sentencia de fecha 22 de diciembre de 2008 (asunto Junta de Vigilancia de la Ultima Sección del Río Mapocho y otros con Superintendencia de Servicios Sanitarios) la Corte de Apelaciones de Santiago destaca no sólo el carácter de sanción de la nulidad de Derecho público, sino que además la exigencia de que el acto administrativo impugnado cause perjuicio, como en toda nulidad. Así señala en el considerando $9^{\circ}$ que: "Empero, puede decirse, a modo de introducción que, como toda nulidad, constituye una sanción, siendo requisito indispensable que el acto que se pretende nulo haya originado o causado un daño o perjuicio. Cabe recordar que constituye un axioma jurídico el que no hay nulidad sin perjuicio, lo cual ocurre con todas las variedades bajo las que se presenta esta institución en el derecho chileno... porque si el acto administrativo es inocuo, carece de todo sentido declararlo nulo de derecho público". 
la ley para su otorgamiento - al haberse prescindido en la especie de la exigencia de un certificado auténtico del COMPIN en que se haga constar la incapacidad física del postulante a la pensión de invalidez-carecen de valor jurídico, lo que puede ser declarado en cualquier momento por el tribunal competente, el cual, al formular tal declaración, se limita a confirmar el mencionado principio de la juridicidad (Considerando 16\%)".

Como ya se ha señalado ${ }^{25}$, le interpretación literal de las causales de nulidad de Derecho público no es errónea, lo que sí lo es, es la consecuencia que ella acarrea: la falta de control judicial de la ilegalidad material del acto administrativo. Sin embargo, la solución está en el mismo art. 7 inc. $3^{\circ} \mathrm{CPR}$, que remite la sanción a la ley, la que en este momento no es otra que el Código Civil, específicamente en su art. 1462.

\section{Conclusiones}

Del examen del estado actual del control de legalidad de los actos administrativos se desprende una conclusión poco halagüeña. Después de una década dorada de los 90, en que la doctrina de la nulidad de Derecho público campeaba casi sin contradicción, ha ido dando paso a un mayor cuestionamiento respecto de sus alcances, causales y fundamentos. Todo ello es demostrativo de la precariedad del Derecho administrativo positivo. En efecto, no se trata ya de volver a reclamar la existencia de tribunales contencioso-administrativos, ello no es una prioridad, y probablemente no lo sea en el mediano plazo para ningún Gobierno. Pero el retroceso del recurso de protección como paliativo a la inexistencia de un contencioso administrativo en forma y el estado actual de la jurisprudencia en la meteria, hacen más imprescindible que nunca el establecimiento al menos de acciones y procedimientos judiciales para la revisión del acto administrativo y para la declaración de derechos de los ciudadanos.

Cuando fue planteada por primera vez una lectura estricta de las causales de nulidad de Derecho público, parecía más bien la posición de un iconoclasta del Derecho administrativo. Sin embargo, la evolución de la jurisprudencia demuestra la necesidad de buscar soluciones que den certeza a los ciudadanos y que los pongan a resguardo frente a una soterrada inimpugnabilidad de la actuación administrativa. La solución más evidente, pero también la más cómoda, es plantear que las soluciones al contencioso administrativo de impugnación sólo pueden ser por la vía legislativa, pero esa no es una solución para quien se encuentra hoy frente a la necesidad de impugnar un acto administrativo. Mientras tanto, la tarea del jurista no es solazarse con sus propias divagaciones dogmáticas, sino la de ofrecer soluciones reales. Es claro que tales soluciones no están hoy día en el Derecho administrativo, sino en la norma remitida.

${ }^{25}$ Bermúdez Soto, J., "El principio de legalidad y la nulidad de Derecho Público en la Constitución Política. Fundamentos para la aplicación de una solución de Derecho Común”, op. cit. pp. 283-285. 


\section{BiBLIOGRAFÍA}

ANDRAdes Rivas, EduARdo, "Comentarios al nuevo auto acordado sobre tramitación del Recurso de Protección”, en Revista Chilena de Derecho, Número Especial, año 1998.

Bermúdez Soto, Jorge, "El principio de legalidad y la nulidad de Derecho Público en la Constitución Política. Fundamentos para la aplicación de una solución de Derecho Común", en Revista de Derecho Público, Volumen 70, año 2008.

Bocanegra Sierra, Raúl, Lecciones sobre el acto administrativo, Ed. Civitas, $2^{\mathrm{a}}$ edición, Madrid, 2004.

Ferrada Bórquez, Juan Carlos, "El recurso de protección como mecanismo de control contencioso administrativo", en Justicia Administrativa, Juan Carlos Ferrada Bórquez, coordinador, Ed. LexisNexis, Santiago, 2005.

Gallego Anabitarte, Alfredo y de Marcos Fernández, Ana, Derecho Administrativo, Materiales, Madrid 1992.

Gallego Anabitarte, Alfredo y Menéndez Rexach, Ángel, Acto y Procedimiento Administrativo, Ed. Marcial Pons, Madrid, 2001.

García de Enterría, Eduardo y Fernández Rodríguez, Tomás Ramón, Curso de Derecho Administrativo, Tomo I, $7^{\text {a }}$ edición, reimpresión de 1996, Ed. Civitas.

Guckelberger, Annette, Die Verjährung im Öffentlichen Recht, Ed. Mohr-Siebeck, Tübingen, 2004.

Marín, Urbano, "Vigencia actual de la invalidación de los actos administrativos", en Revista de Derecho del Consejo de Defensa del Estado, No 2, año 2002.

Maurer, Hartmut, Verwaltungsrecht, 12ª edición, Ed. Beck, Munich, 1999.

Mayer, Otto, Derecho Administrativo Alemán, Tomo I, Ed. Depalma, Buenos Aires, 1949.

Nogueira Alcalá, Humberto, "El Recurso de Protección en el Contexto del Amparo de los Derechos Fundamentales Latinoamericano e Interamericano", en Ius et Praxis, volumen 13 $\mathrm{N}^{\circ} 1,2007$.

Puppio, Vicente, Teoría General del Proceso, $7^{a}$ Edición, Universidad Católica Andrés Bello, Caracas, 2008.

Soto Kloss, Eduardo, Derecho Administrativo, Bases Fundamentales, Tomo II, El principio de Juridicidad, Ed. Jurídica de Chile, Santiago, 1996.

Soto Kloss, EduARdo, "La Ley 19.880 sobre procedimientos administrativos, ¿Aleluya o Miserere?", en Ley 19.880 sobre procedimientos administrativos, Conferencias, Academia de Derecho Santo Tomás de Aquino, año 2003.

Soto Kloss, Eduardo, "La nulidad de Derecho público en el derecho chileno", Revista de Derecho Público, Nos. 47-48, enero-diciembre de 1990.

Vergara Blanco, Alejandro, "Derecho administrativo y supuesta supletoriedad general del Código Civil”, en Revista de Derecho Administrativo, 2009, N³. 
